\title{
PERBANDINGANANTARA INFORMASI SUHU PERMUKAAN LAUT DARI DATA SATELIT DENGAN HASIL PEMODELAN DI WPP NRI-716
}

\author{
Komang Iwan Suniada \\ Balai Penelitian dan Observasi Laut (BPOL) \\ Badan Penelitian dan Pengembangan Kelautan dan Perikanan \\ e-mail: komang_prtk@yahoo.com
}

\begin{abstract}
Abstrack
Sea Surface Temperature (SST) data and information recently become a valuable information since its association with the climate, oceanography condition and fisheries have been discovered. Unfortunately, SST information using satellite imagery frequently constrained by atmospheric cloud cover since satellite sensor disability to gather any land or ocean surface information through the cloud. Modeling data is very required to fill the blank data resulted from satellite imagery under cloudy condition. This study conducted at Sulawesi Sea to North Halmahera which is included to Fisheries Managing Area (FMA) 716, to find out the strength and direction relationship between SST model and SST satellite. Result indicates there is a strong and same direction relationship between SST model and SST satellite $(r=0.704, n=1516)$ with $0.2^{\circ} \mathrm{C}$ diferrence so that SST model can be used to fill or substitute the blank of SST satellite
\end{abstract}

Keyword : Sea Surface Temperature, SST satellite, SST model, FMA 716

\begin{abstract}
Abstrak
Data dan informasi mengenai Suhu Permukaan Laut (SPL) saat ini terasa sangat penting karena mempunyai hubungan yang erat dengan iklim, kondisi oseanografis perairan bahkan dalam bidang perikanan. Namun informasi SPL melalui data satelit seringkali terkendala oleh tutupan awan, karena ketidakmampuan sensor satelit untuk menembus awan. Untuk melengkapi kekosongan data akibat tutupan awan tersebut diperlukan adanya alternatif data yang bebas awan, misalnya data SPL yang dihasilkan dari model. Kajian ini dilakukan untuk mengetahui kekuatan dan arah hubungan antara data satelit dan data model dengan menggunakan analisis korelasi diantara keduanya. Lokasi kajian adalah di wilayah Laut Sulawesi hingga Utara Halmahera yang termasuk kedalam Wilayah Pengelolaan Perikanan Negara Republik Indonesia (WPP NRI)-716. Hasil kajian menunjukkan bahwa kedua data tersebut mempunyai hubungan yang kuat dan searah $(\mathrm{r}=0.704, \mathrm{n}=1516)$ dengan selisih $0.2^{\circ} \mathrm{C}$, sehingga data model dapat digunakan untuk mengisi ataupun mensubstitusi kekosongan data satelit
\end{abstract}

Kata kunci : Suhu Permukaan Laut, data satelit, data model, WPP NRI-716 


\section{Pendahuluan}

Saat ini informasi mengenai sebaran Suhu Permukaan Laut (SPL) menjadi sangat penting karena telah diketahui mempunyai hubungan yang erat dan saling mempengaruhi dengan iklim (Mulyana, 2000; Ummenhofer et al, 2008; Qu et al, 2012), informasi mengenai kondisi oseanografis suatu wilayah perairan misalnya kejadian upwelling (Uiboupin and Laanemets, 2009; Kunarso et al, 2011; Benazzouz et al, 2014), front (Cayula and Cornillon, 1992; Jatisworo dan Murdimanto, 2013) serta erat kaitannya dengan produktifitas perikanan (Mugo et al, 2010; Wibawa, 2011; Zainuddin et al, 2013). Salah satu sumber informasi mengenai sebaran suhu permukaan laut dapat diperoleh dengan memanfaatan data citra satelit yang memiliki kelebihan mampu memberikan informasi secara cepat, daya jangkauan yang luas serta biaya murah (Kasim, 2010). Namun untuk wilayah yang beriklim tropis seperti Indonesia, masalah tutupan awan seringkali menjadi salah satu kendala untuk memperoleh informasi suhu permukaan laut karena pantulan gelombang elektromagnetik dari permukaan laut yang seharusnya sampai mencapai sensor satelit terhalang oleh awan. Informasi yang tidak mampu diperoleh melalui citra satelit tersebut diharapkan mampu dilengkapi oleh ketersediaan data suhu permukaan laut yang disusun dengan menggunakan pemodelan matematis dan bebas awan (cloud free). Salah satu proses penyusunan data suhu permukaan laut global yang bebas awan adalah dengan menggunakan OSTIA (Operational SST and Sea Ice Analysis) system (Robert-Jones et al, 2012). Data suhu permukaan laut global yang bebas awan ini dikenal dengan nama data level 4 dan disusun dengan menggunakan berbagai macam data yang bersumber dari berbagai macam sensor satelit seperti sensor AMSR-E dari satelit AQUA, sensor AATSR dari satelit ENVISAT, sensor SEVIRI dari satelit MSG, sensor AVHRR-3 dari satelit NOAA 16, 17, 18 dan sensor TMI dari satelit TRMM serta telah divalidasi dengan menggunakan data insitu yang bersumber dari data Argo float. Resolusi spasial data suhu permukaan laut yang bebas awan ini adalah $1 / 12^{\circ}$ atau sekitar $9 \mathrm{~km}$ termasuk sangat baik untuk observasi global, namun masih belum cukup baik untuk observasi pada kawasan pesisir dan perairan yang sempit.
Tujuan dari penelitian ini adalah untuk membandingkan dan mengetahui hubungan antara data suhu permukaan laut yang bersumber dari citra satelit dengan data suhu permukaan laut yang bersumber dari pemodelan matematis. Dengan adanya data suhu permukaan laut yang bebas awan ini diharapkan dapat mengisi kekosongan data suhu permukaan laut dari citra satelit akibat tutupan awan. Namun sebelum itu, perlu dilakukan suatu kajian mengenai kekuatan dan arah hubungan diantara data SPL satelit dan SPL model untuk memastikan apakah data SPL hasil model dapat digunakan untuk mengisi kekosongan data SPL satelit.

\section{Metodologi}

Data SPL satelit dan SPL model diperoleh dengan cara mengunduh dari web portal INDESO (www.indeso.web.id) setelah melakukan registrasi. Data SPL satelit yang tersedia pada web portal INDESO tersebut bersumber dari sensor MODIS yang terdapat pada satelit Aqua dan Terra serta dari sensor AVHRR yang terdapat pada satelit METOPA, sedangkan data SPL model bersumber dari berbagai macam sensor satelit seperti sensor AMSRE dari satelit AQUA, sensor AATSR dari satelit ENVISAT, sensor SEVIRI dari satelit MSG, sensor AVHRR-3 dari satelit NOAA 16, 17, 18 dan sensor TMI dari satelit TRMM. Data yang digunakan adalah data bulan Januari - April 2014 dengan lokasi penelitian berada pada di Laut Sulawesi hingga Utara Pulau Halmahera yang termasuk kedalam Wilayah Pengelolaan Perikanan Negara Republik Indonesia (WPP NRI)-716. Masing-masing dataset diesktrak nilai suhu permukaan lautnya pada 43 titik lokasi yang tersebar merata di dalam area WPP NRI-716 (gambar 1.)

Proses persiapan data dan ekstraksi nilai suhu permukaan laut ini dilakukan pada perangkat lunak image processing dan selanjutnya dilakukan penghitungan koefisien korelasi Pearson menggunakan persamaan 1) yang dilakukan pada perangkat lunak statistik untuk mengetahui hubungan diantara keduanya (Walpole, 1993)

$$
\text { Korelasi } \left.=r_{y y}=\frac{n \sum x_{i} y_{i}-\sum x_{i} \sum y_{i}}{\sqrt{n \sum x_{i}^{2}-\left(\sum x_{i}\right)^{2}} \cdot \sqrt{n \sum y_{i}^{2}-\left(\sum y_{i}\right)^{2}}} \ldots \ldots 1\right)
$$




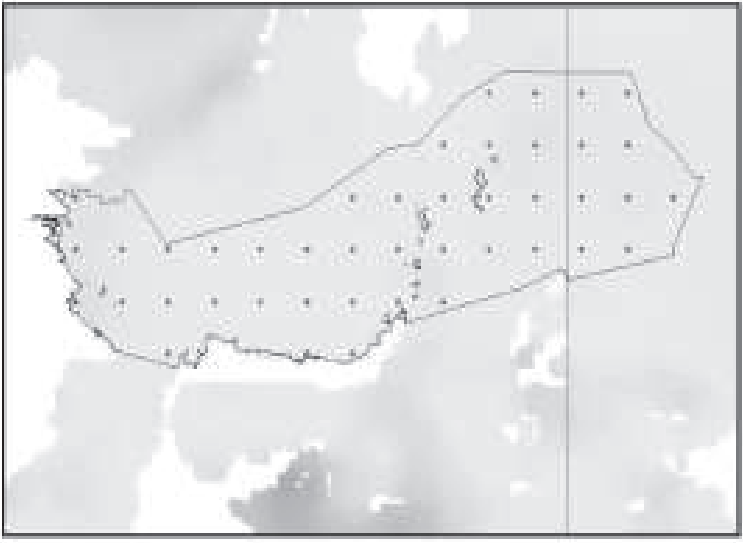

a. Data Model

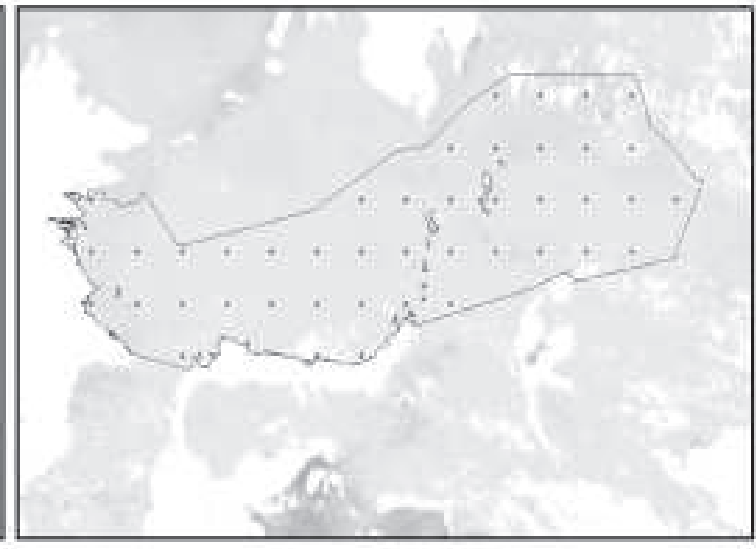

b. Data Citra Satelit

Gambar 1. Titik-titik sampel data suhu permukaan laut

Asumsi yang biasa digunakan untuk analisis korelasi adalah sampel data berpasangan $(\mathrm{x}, \mathrm{y})$ berasal dari sampel acak dan merupakan data kuantitatif serta pasangan data $(x, y)$ harus berdistribusi normal. Koefisien korelasi digunakan untuk mengukur kekuatan dan arah hubungan linier dari dua variabel serta tidak selalu ada hubungan sebab akibat diantara kedua variabel tersebut. Korelasi hanya menjelaskan kekuatan hubungan tanpa memperhatikan hubungan kausalitas, mana yang dipengaruhi dan mana yang mempengaruhi. Kedua variabel masing-masing bisa berperan sebagai Variabel X maupun Variabel Y. Selisih antara SPL model dan SPL satelit dilakukan untuk mengetahui perbedaan diantara kedua data tersebut dan dihitung dengan menggunakan operasi pengurangan sederhana pada setiap pasangan data.

\section{Hasil dan Pembahasan}

Data suhu permukaan laut satelit dan hasil pemodelan yang berhasil dikumpulkan dari web portal INDESO adalah sebanyak 46 dataset, dengan rincian seperti yang terlihat pada tabel 1. Jika pada masing-masing dataset terdiri dari 43 titik SPL, maka akan diperoleh informasi SPL sebanyak 1978 pasang titik SPL dalam kurun waktu Januari - April 2014. Selanjutnya dilakukan proses filtering data untuk meyakinkan bahwa semua data berpasangan agar tidak terjadi kesalahan dalam proses selanjutnya. Dalam proses filtering data, ditemukan titik-titik SPL yang tidak ada nilainya karena tutupan awan sehingga data tersebut harus dieliminasi. Setelah dilakukan proses filtering jumlah titik SPL yang tersisa tinggal 1516 pasang, data inilah yang selanjutnya siap untuk dianalisis lebih lanjut.

Tabel 1. Jumlah dataset yang dikumpulkan

\begin{tabular}{lcc}
\hline Bulan & SPL satelit & SPL model \\
\hline Januari & 13 & 13 \\
Februari & 12 & 12 \\
Maret & 13 & 13 \\
April & 8 & 8 \\
\hline Total & 46 & 46 \\
\hline
\end{tabular}

Salah satu syarat yang harus dipenuhi sebelum melakukan uji korelasi adalah apakah data tersebut menyebar normal atau tidak, untuk mengetahui hal tersebut perlu dilakukan terlebih dahulu dilakukan uji distribusi normal. Hasil uji distribusi normal dengan metode Kolmogorov-Smirnov menunjukkan bahwa nilai signifikansi sebesar 0.195 lebih besar dari 0.05 sehingga dapat disimpulkan bahwa data yang sedang diuji terdistribusi normal (gambar 2.) dan selanjutnya dilakukan analisis korelasi terhadap kedua data tersebut. 


\begin{tabular}{|c|c|c|}
\hline & \multicolumn{2}{|c|}{$\begin{array}{c}\text { Unstandardized } \\
\text { Residual }\end{array}$} \\
\hline $\mathrm{N}$ & 1516 & \\
\hline Normal Parameters ${ }^{\mathrm{a}, \mathrm{b}}$ & Mean & .0000000 \\
\hline & $\begin{array}{l}\text { Std. } \\
\text { Deviation }\end{array}$ & .32511490 \\
\hline \multirow[t]{3}{*}{ Most Extreme Differences } & Absolute & .028 \\
\hline & Positive & .028 \\
\hline & Negative & -.024 \\
\hline Kolmogorov-Smirnov Z & & 1.079 \\
\hline Asymp. Sig. (2-tailed) & & .195 \\
\hline
\end{tabular}

a. Test distribution is Normal.

b. Calculated from data.

\section{Gambar 2. Hasil Uji Sebaran Normal}

Hasil analisis korelasi dengan memanfaatkan perangkat lunak statistika menunjukkan bahwa terdapat korelasi yang signifikan antara data SPL satelit dan SPL model dengan nilai koefisien korelasi, $\mathrm{r}=0.704$ dari 1516 pasangan data (gambar 3). Hubungan yang signifikan ini berarti bahwa ada hubungan linier dan searah yang kuat diantara data SPL model dan SPL satelit, jika nilai SPL model meningkat maka nilai SPL satelit juga akan meningkat dan sebaliknya.

Perbedaaan nilai SPL model dan SPL satelit berkisar antara $-1.5^{\circ} \mathrm{C}$ sampai $1.7^{\circ} \mathrm{C}$ (Gambar 4.), dengan rata-rata SPL model sebesar $28.5^{\circ} \mathrm{C}$ dan ratarata SPL satelit sebesar $28.3^{\circ} \mathrm{C}$ atau secara rata-rata terdapat selisih sebesar $0.2^{\circ} \mathrm{C}(\mathrm{n}=1516)$. Perbedaan tersebut diduga karena pada SPL model menggunakan inputan yang lebih banyak dibandingkan dengan SPL satelit serta kemungkinan disebabkan karena adanya perbedaan resolusi spasial diantara keduanya.

Selisih $0.2^{\circ} \mathrm{C}$ antara data SPL model dan SPL satelit pada penelitian ini serupa dengan dengan hasil penelitian Adi, et al. (2014) dalam membangun model parameterisasi empirik di Samudera Hindia yang membandingkan antara data model dan data insitu dengan nilai error $0.21^{\circ} \mathrm{C}\left(\mathrm{r}^{2}=0.81\right)$.

\begin{tabular}{llrr}
\hline & & SST_Mod & SST_Sat \\
\hline \multirow{2}{*}{ SST_Mod } & Pearson Correlation & 1 & $.704^{* *}$ \\
& Sig. (1-tailed) & & .000 \\
& N & 1516 & 1516 \\
SST_Sat & Pearson Correlation & $.704^{* * *}$ & 1 \\
& Sig. (1-tailed) & .000 & \\
& N & 1516 & 1516 \\
\hline
\end{tabular}

**. Correlation is significant at the 0.01 level (1-tailed).

Gambar 3. Hasil Uji Korelasi antara SPL model dan SPL satelit

Perbedaan $0.2^{\circ} \mathrm{C}$ tersebut masih termasuk kedalam kategori baik dan dapat diterapkan, sehingga dalam hal ini karena SPL model dan SPL satelit mempunyai hubungan linier yang kuat dengan selisih $0.2^{\circ} \mathrm{C}$ maka kekosongan data pada SPL satelit dapat dilengkapi oleh SPL model.

Perbedaan yang sangat jelas antara SPL model dan SPL satelit pada tanggal 10 Januari 2014 dapat dilihat pada Gambar 5.

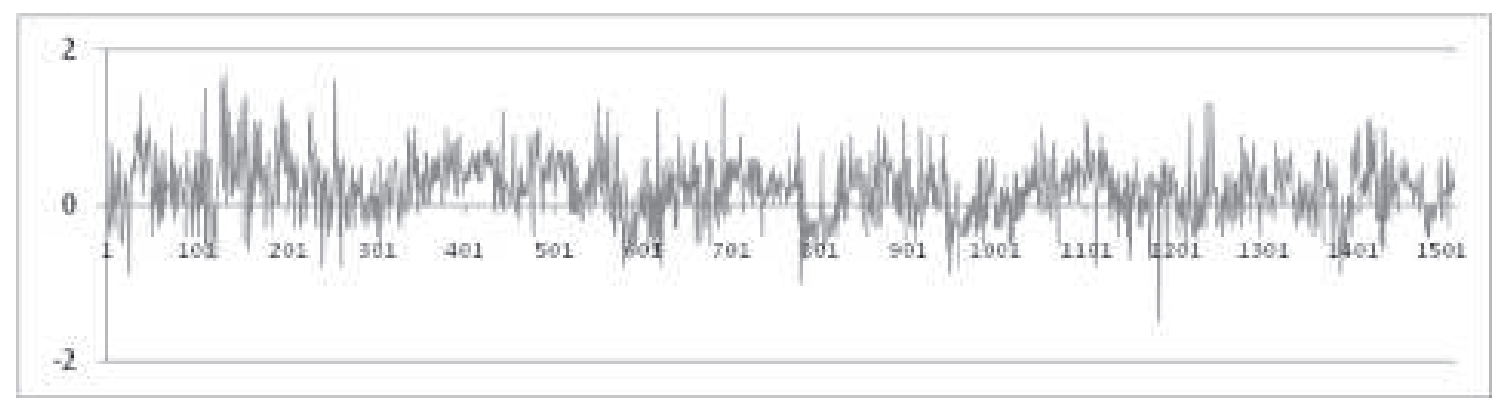

Gambar 4. Selisih antara SPL model dan SPL satelit 


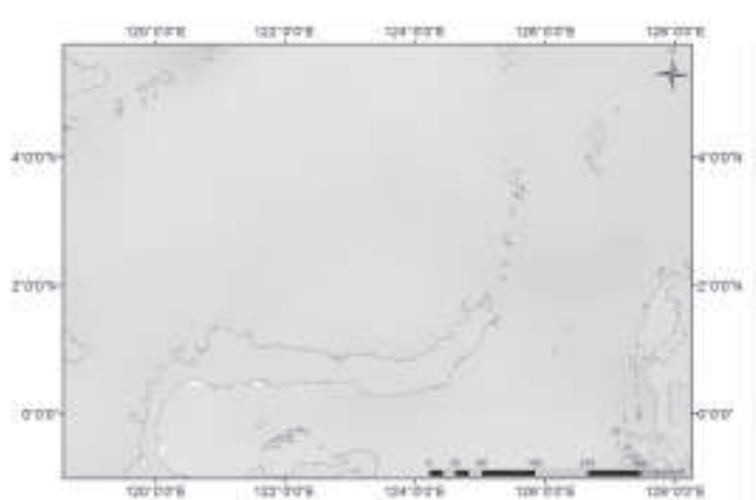

a. SPL model tgl 10 Januari 2014

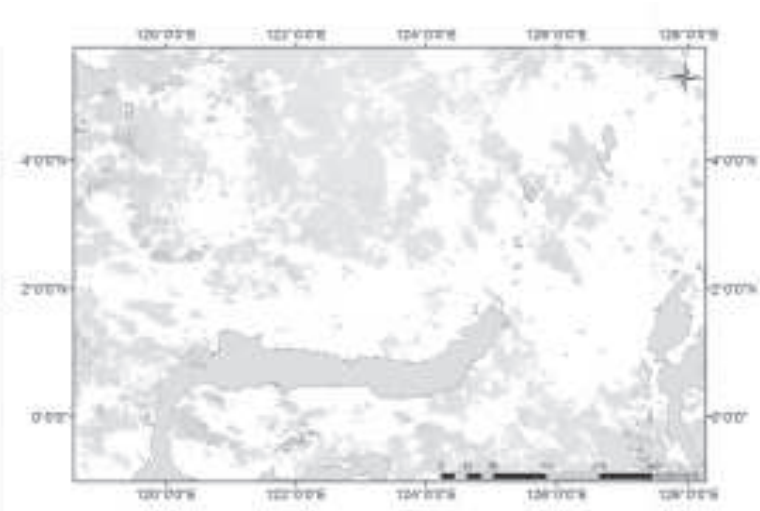

b. SPL satelit tgl 10 Januari 2014

Gambar 5. Perbedaan antara SPL model dan SPL satelit (dimodifikasi dari www.indeso.web.id)

Karena tutupan awan yang tinggi, maka banyak informasi yang tidak dapat diperoleh hanya dengan memanfaatkan data SPL satelit, sehingga memerlukan informasi yang bersumber dari data yang lain, yaitu data SPL model.

\section{Simpulan}

Hubungan yang signifikan antara SPL model dan SPL satelit menunjukkan bahwa kedua data tersebut memiliki hubungan linier yang kuat dan searah $(r=0.704, n=1516)$ dengan selisih $0.2^{\circ} \mathrm{C}$. Karena hubungan linier yang kuat dan searah tersebut, maka kedua data akan mempunyai kecenderungan pola sebaran yang sama, yaitu jika nilai SPL satelit tinggi pada suatu lokasi, nilai SPL model pada lokasi yang sama juga akan tinggi dan demikian juga sebaliknya, sehingga kekosongan data SPL satelit dapat disubstitusi oleh data SPL model. Namun karena resolusi yang lebih rendah, maka SPL model tidak cukup baik digunakan untuk observasi di wilayah yang sempit dan kecil, misalnya wilayah pesisir ataupun selat.

\section{Daftar Pustaka}

Adi, T.R., B.M. Sukoco, T. Hariyanto, S. Wirasantosa, W.S. Pranowo, W. Yu and M. Mustain. 2014. Model Variasi Harian Suhu Permukaan Laut dari Data Modis dan In Situ Menggunakan Metoda Parameterisasi Empirik di Samudera Hindia. Jurnal Segara vol.10. hal 87-97.
Benazzouz, A., S. Mordane, A. Orbi, M. Chagdali, K. Hilmi, A. Atillah, J.L. Pelegri, H. Demarcq. 2014. An Improved Coastal Upwelling Index from Sea Surface Temperature using Satellite-Based Approach - The Case of the Canary Current Upwelling System. Elsevier, Continental Shelf Research 81. P 38-54.

Cayula, J.-F., \& Cornillon, P. (1992). Edge Detection Algorithm for SST Images. Journal of Atmospheric and Oceanic Technology, 9(1), 67-80.

Jatisworo, D., \& Murdimanto, A. (2013). Identifikasi thermal front di Selat Makassar dan Laut Banda. Prosiding Simposium Nasional Sainds Geoinformasi III.

Kasim, F. 2010. Analisis Distribusi Suhu Permukaan menggunakan Data Citra Satelit Aqua-MODIS dan Perangkat Lunak Seadas di Perairan Teluk Tomini. Jurnal Ilmiah Agropolitan vol.3. hal 270-276.

Kunarso, S. Hadi, N.S. Ningsih and M.S. Baskoro. 2011. Variabilitas Suhu dan Klorofil-a di Daerah Upwelling pada Variasi Kejadian ENSO dan IOD di Perairan Selatan Jawa sampai Timor. Jurnal Ilmu Kelautan vol 16(3). hal 171-180.

Mugo, R., Saitoh, S.I., Nihira, A., \& Kuroyama, T. (2010). Habitat characteristics of skipjack tuna (Katsuwonus pelamis) in the western North Pacific: a remote sensing perspective. Fisheries Oceanography, 19(5). p 382-396. 
Mulyana, E. 2000. Hubungan antara Anomali Suhu Permukaan Laut dengan Curah Hujan di Jawa. Jurnal Sains \& Teknologi Modifikasi Cuaca, Vol 1, No.2. hal 125-132.

Qu, B., A.J. Gabric, J. Zhu, D. Lin, F. Qian and M. Zhao. 2012. Correlation Between Sea Surface Temperature and Wind Speed in Greenland Sea and Their Relationship with NAO Variability. Water Science and Engineering 5(3). P 304-315.

Robert-Jones, J., E.K. Fielder and M.J. Martin. 2012. Dialy, Global, High-Resolution SST and Sea Ice Reanalysis for 1985-2007 Using OSTIA System. Journal of Climate vol.25. p 6215-6232.

Ummenhofer, C.C., A.S. Gupta, M.H. England and C.J.C. Reason. 2008. Contributions of Indian Ocean Surface Temperatureto Enhanced East African Rainfall. Journal of Climate vol.22. p 993-1013.
Uiboupin, R. and J. Laanements. 2009. Upwelling Characteristics Derived from Satellite Sea Surface Temperature Data in the Gulf of Finland, Baltic Sea. Boreal Environment Research 14. p 297-304.

Walpole, R.E. 1993. Pengantar Statistika. PT. Gramedia Pustaka Utama, Jakarta.

Wibawa, T.A. (2011). Pemanfaatan Data Satelit Oseanografi untuk Prediksi Daerah Potensial Penangkapan Tuna Mata Besar (T. obesus) di Samudera Hindia Selatan Jawa Bali. Jurnal Segara, 7(1),. Hal 29-41.

Zainuddin, M., Nelwan, A., Farhum, S.A., Najamuddin, Hajar, M.A.I., Kurnia, M., \& Sudirman. (2013). characterizing potential fishing zone of skipjack tuna during the southeast monsoon in the Bone Bay-Flores Sea using remotely sensed oceanographic data. International Journal of Geosciences vol 4. $p$ 259-266. 